\section{Arqueología, Arquitectura e Historia en el Archivo Histórico Provincial de Jaén}

\author{
M. a TeRESA CAMPOS LÓPEZ
}

\begin{abstract}
Resumen
A partir de la necesidad de restaurar y presentar una propuesta de conservación para uno de los inmuebles más emblemáticos de la capital jiennense, se descubre lo que, a juicio de los investigadores, son los últimos restos de los «antiguos palacios árabes», y a través de un estudio combinado de estratigrafía muraria, intervención arqueológica y el estudio de las fuentes documentales, se ha podido constatar la secuencia histórica del edificio que es sede del Archivo Histórico Provincial, localizado en una de las zonas de más relevancia histórica de la ciudad. La ocupación documentada abarca desde niveles romanos, almohades, siendo más tarde palacio real, convento, universidad, plaza fuerte de la resistencia en la Guerra de la Independencia, hospicio de hombres y, finalmente, Archivo Histórico.

Es un ejemplo de cómo los edificios se mantienen vivos dentro de la trama urbana, adaptándose, transformándose y de la lectura de estas secuencias y de las improntas que este devenir deja en sus paramentos, en el subsuelo, ...
\end{abstract}

Palabras clave: Arquitectura, Arqueología, Historia, Estudio murario, Transformación.

\footnotetext{
Abstract

From the necessity for restoration and the need to present a conservation proposal for one of the most symbolic buildings in Jaén, Andalucía, a discovery was made of what are, according to researchers, the last remains of the «ancient Arab palaces». Through a combined study of wall stratigraphy, archaeological intervention and the study of documentary sources, it has been possible to prove the historical sequence of the building which is the central office of the Provincial History Archive, located in one of the most historically relevant areas of the city. The building has been occupied since Roman times, later housing the Almohade Muslim dynasty, a royal palace, a convent, a university, a stronghold of resistance during the War of Independence, a men's hospice and presently the History Archive.

This is one example of how buildings stay alive in urban areas, adapting and transforming, and of the reading of these sequences and the mark that this constant state of development leaves on the facings, in the cellars...
}

Key words: Architecture, Archaeology, History, Wall study, Transformation.
El estudio que a continuación se presenta es, a nuestro parecer, de un gran interés, ya que ha permitido documentar arqueológicamente una historia compleja y continuada en la ocupación del emplazamiento donde se levanta actualmente uno de los edificios más significativos de la capital jiennense, que queda como ejemplo de la historia viva de la evolución urbana de la ciudad.

La estructuración de este artículo ha intentado ser lo más fiel posible al póster que con el mismo título y con la misma temática fue presentado en Seminario Internacional sobre Arqueología de la Arquitectura, celebrado en VitoriaGasteiz en Febrero de 2002.

\section{ARQUITECTURA}

Con fecha de dos de Mayo de 1995 la Delegación Provincial de Cultura en Jaén de la Junta de Andalucía expone una primera propuesta de intervención en el Archivo Histórico Provincial de Jaén a efectos de la realización de obras de conservación y, en concreto, la eliminación de las humedades existentes en el muro colindante con la calle Santo Domingo. Siendo ésta una de las actuaciones a realizar dentro de un total de cinco previstas para esa fase según el proyecto del arquitecto encargado del mismo, D. Pedro Salmerón Mallol.

Así, en Abril de 2001 comienzan las obras centradas en los siguientes puntos: la eliminación de humedades en el muro colindante con la calle Santo Domingo, el saneamiento de la solería del claustro y el tratamiento del muro de la sala de lectura y de conferencias del Archivo. Nosotros, debido a la finalidad de este estudio, vamos a centrarnos en las dos primeras.

Las manchas de humedad aparecían de forma continuada y extendida a lo largo de toda la longitud del muro y no se observaba que arrancaran claramente de la base sino que, más bien, se generalizaba su aparición de arriba abajo, desde el borde de los arcos o bien desde las zonas centrales. Existían disgregaciones de mortero y apulgaramiento y abombamiento del revoco. El origen era diverso: lluvia, capilaridad por nivel freático, capilaridad ascendente simple y humedades del terreno debido a roturas con presión.

Así, la actuación proponía el picado del muro hasta descubrir la fábrica original en toda su altura (hasta el arranque de las bóvedas, aproximadamente una altura de $+3,85 \mathrm{~m}$ y que coincide con el nivel de la calle Santo Domingo). Posteriormente se regularizaría y trataría la superficie para atajar esas humedades.

Tras la eliminación del estuco y enlucido que cubría el muro, se observó, que frente a lo cabría esperar como fábrica original realizada a partir una sillería regular a soga y trabada con argamasa, aparecían dos cajones de tapial además 
de múltiples arreglos y reparaciones e, incluso, roturas en el muro para encajar tuberías modernas.

Si tenemos en cuenta el edificio donde se emplaza el Archivo Histórico Provincial entenderemos la importancia de este estudio, especialmente si atendemos a su conjunto, a la sucesión de la secuencia estratigráfica y a sus relaciones físicas e históricas.

Según Madoz (1849) «...el Convento [localizado donde hoy se encuentra el Archivo Histórico] se fundó en 1382 con el título de Santa Catalina, mártir, y orden de Predicadores. Fue cedido con este objeto por el Rey D. Juan I, de quien fue palacio, adquirido a los reyes moros, a quienes perteneció. La iglesia es de planta rectangular. (...). El patio del convento es cuadrado y espacioso, obra del maestro que hizo la fachada de la catedral: está cerrado por un ancho claustro, sostenido por 28 arcos y 60 columnas toscanas pareadas y a tres en los ángulos(...). En el centro del patio hay una fuente de agua abundante. Este edificio fue hospicio de hombres [1847]. Tuvo escuelas de filosofia y teologia y honores de Universidad por concesión del Papa Paulo III...[siglo XVI]». Se abandona como hospicio en 1970. Tras esta fecha fue objeto de restauración bajo la dirección de D. Luis Bérges Roldán para convertirse en sede del Archivo Histórico Provincial.

\section{ARQUEOLOGÍA}

El estudio arqueológico se realizó cubriendo dos vertientes: el estudio murario del muro sur del claustro, colindante con la calle Santo Domingo y la realización de dos catas o sondeos arqueológicos que nos permitieran conocer la secuencia estratigráfica del claustro así como confirmar y/o contrastar los resultados del estudio murario y del estudio documental realizado en torno a la historia del edificio.

Así, en lo referente al estudio murario y puesto que el muro sur se encontraba tan alterado, se consideró que lo principal era aclarar el comportamiento de las diferentes estructuras documentadas, a cuya definición nos ayudó especialmente el estudio de las diferentes técnicas constructivas ya que sus diferencias eran más que patentes.

Fase I: Se corresponde con los dos cajones de tapial hormigonados documentados, en el interior aparece una mampostería con enfoscado en vitolas, mientras que la cara externa aparece lisa y ausente de mampuestos. Tapial de color rojizo, donde aparecen fragmentos de cerámica, grava, cales,... Adscrito a una cronología almohade y reutilizado, posiblemente debido a su gran consistencia.

Fase II: Representada por una fábrica de sillares a soga de gran tamaño trabados con mortero. Consideramos que reflejan las grandes reformas que se realizaron tras la cesión del edificio por parte de Juan I para que fuera construido en él el Convento de Santa Catalina.

Fase III: Es quizás la más compleja y podría subdividirse en varias subetapas pero la falta de datos más concretos no nos permite ajustar estas divisiones. Cronológicamente la englobamos entre el siglo XIX y XX. Sabemos que cuando el inmueble fue declarado hospicio de hombres (1847) sufrió una gran reforma, pero en esta fase se documentan multitud de reformas, reparaciones y daños a elementos primitivos del muro (especialmente a la altura del segundo cajón de tapial, que queda más próximo a la cota de suelo del claustro) debido al acondicionamiento del edificio a sus nuevos usos (apertura para bajadas de tuberías, cableado, etc). Es decir, es una fase donde se han estudiado las alteraciones y daños realizados a fases y elementos constructivos anteriores para la adecuación a un nuevo uso del inmueble.

En lo referente a los sondeos arqueológicos (dos sondeos de $22 \mathrm{~m}$ y ampliados posteriormente) y donde se pretendía documentar la potencia del muro sur así como su sistema de cimentación.

El muro sur quedaba colgado a escasa altura, es decir, el cajón de tapial terminaba a la misma altura que el suelo de cal grasa y adscrito al período en que el edificio era el Convento de Santa Catalina (siglos XIV y XV). Esta escasa potencia se explica por el hecho de que, como se ha documentado en la intervención, no existe una colmatación de niveles uno encima del otro, es decir, debido a la diferencia de cota con la calle $(-2,94 \mathrm{~m})$ la ocupación en el tiempo se ha resuelto arrasando el nivel anterior, por lo que, en aproximadamente $0,5 \mathrm{~m}$, documentamos una serie de niveles que posiblemente se correspondan con el último siglo pero que ocupan el espacio físico de otros anteriores y eliminados a priori. Parece ser ésta una práctica continuada a lo largo de la historia del edificio.

La cimentación del muro se realizó sobre una base de ladrillos (de altura variable y adaptada a la orografía del terreno) asentada sobre un estrato o paquete de colmatación de estructuras anteriores (niveles romanos) y que utilizan como zapata.

Esta ocupación romana (fase I) está definida por una preparación de opus caementicium que aislaba y protegía de la humedad de esta zona (el nivel freático se localiza a esta cota), sobre el cual se documentaron los restos de la cimentación de un muro (expoliado), asociado a un pavimento de empedrado. El nivel de colmatación de dichas estructuras puede ser tanto de cronología tardorromana como alto medieval, fue reutilizado en época islámica (siglos XI-XII), claramente vinculado a la construcción de los cajones de tapial que aparecieron en el muro sur (fase II). 

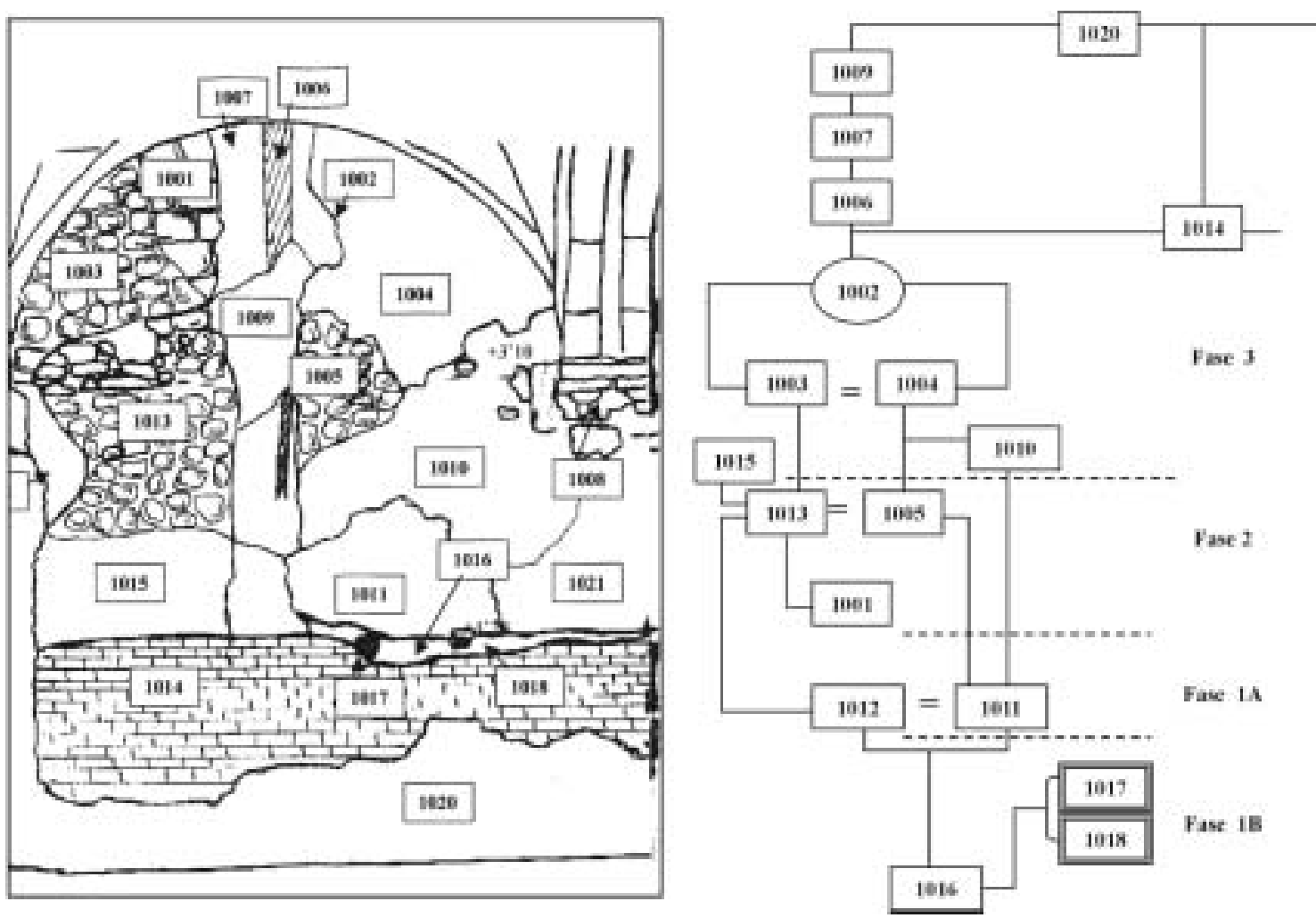

Fig. 1. Croquis de trabajo de la zona de crucería del ángulo sureste del claustro y sus matrices correspondientes
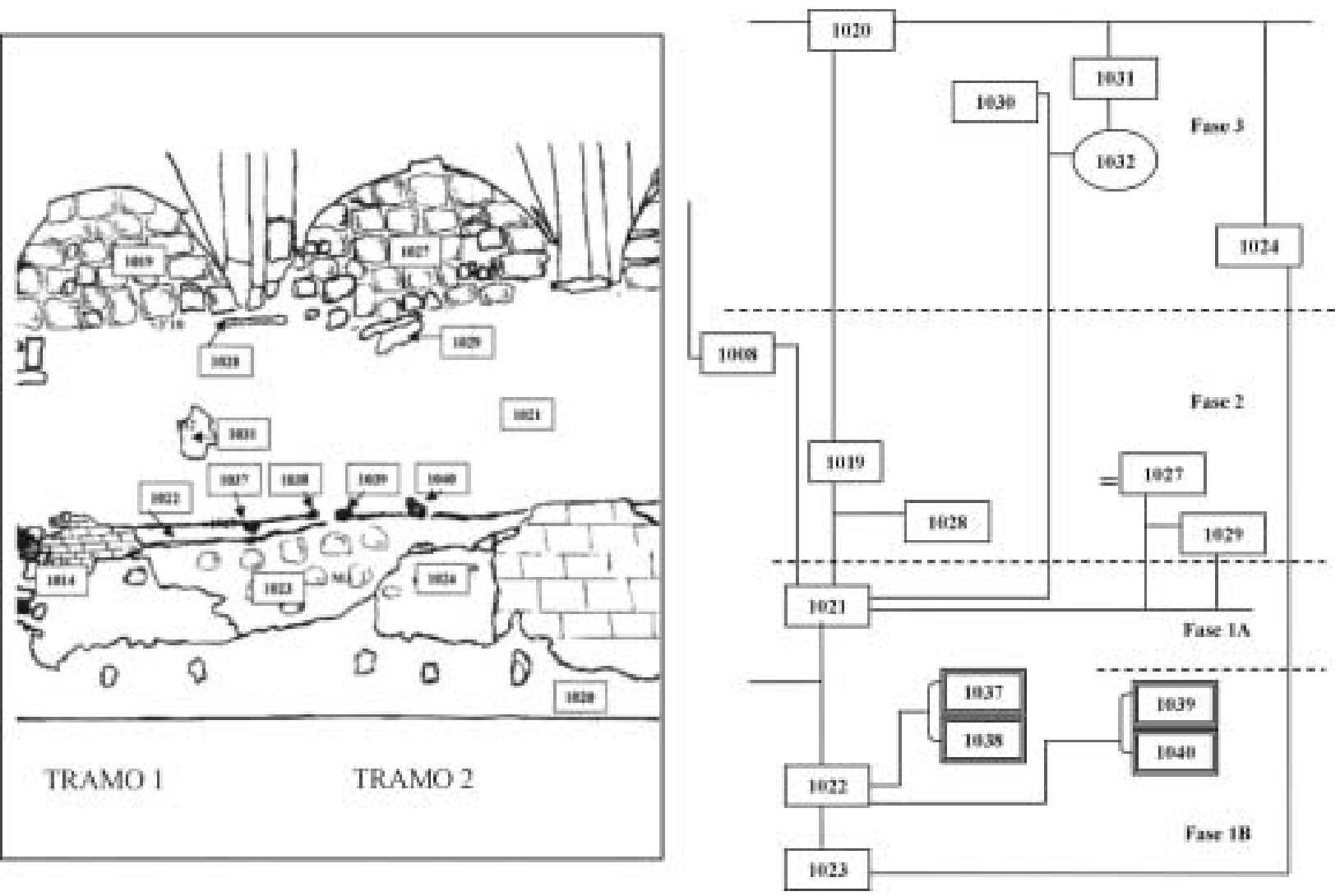

Fig. 2. Croquis de trabajo de dos de los tramos de arcadas del muro sur del claustro y sus matrices correspondientes 


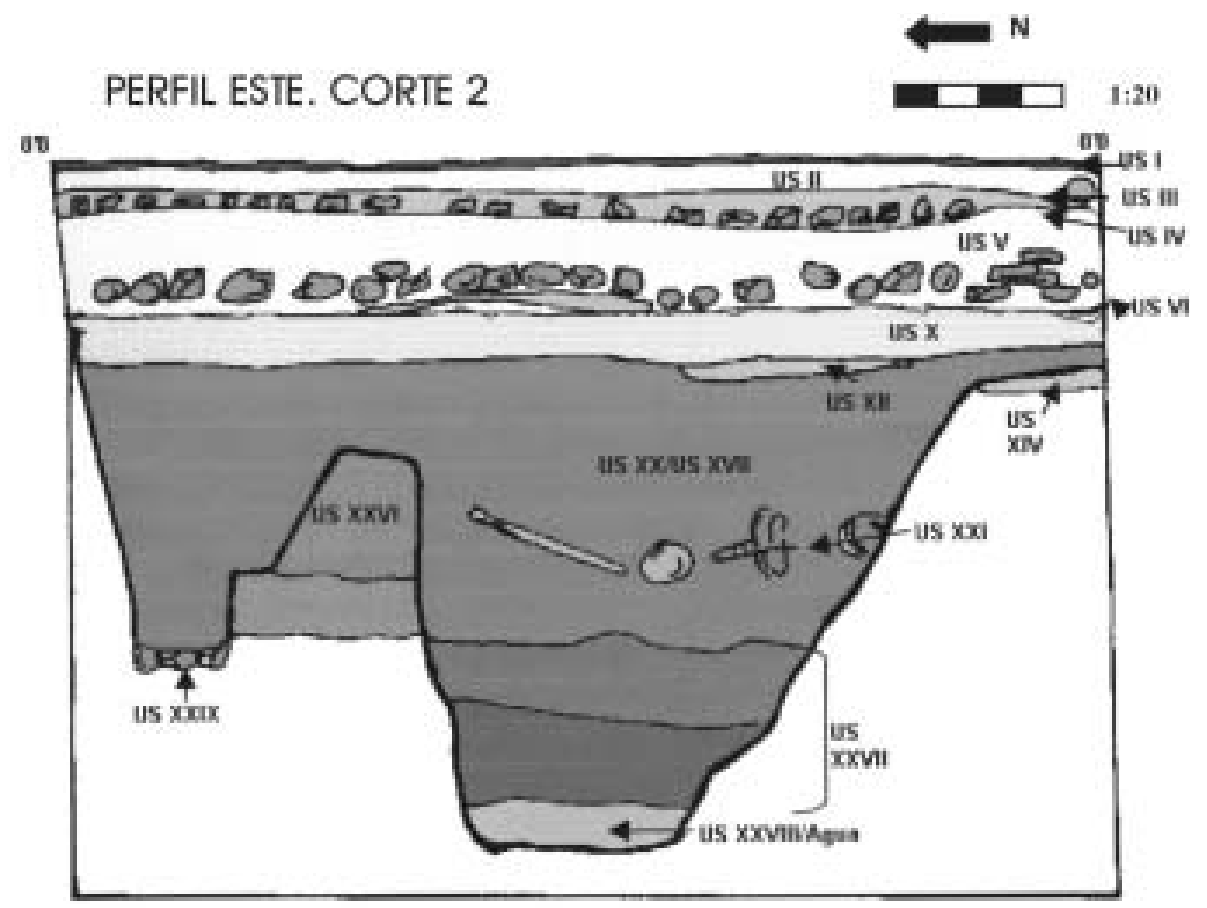

Fig. 3. Perfil este del corte arqueológico 2

\section{PLANTA 2.1. CORTE 2}

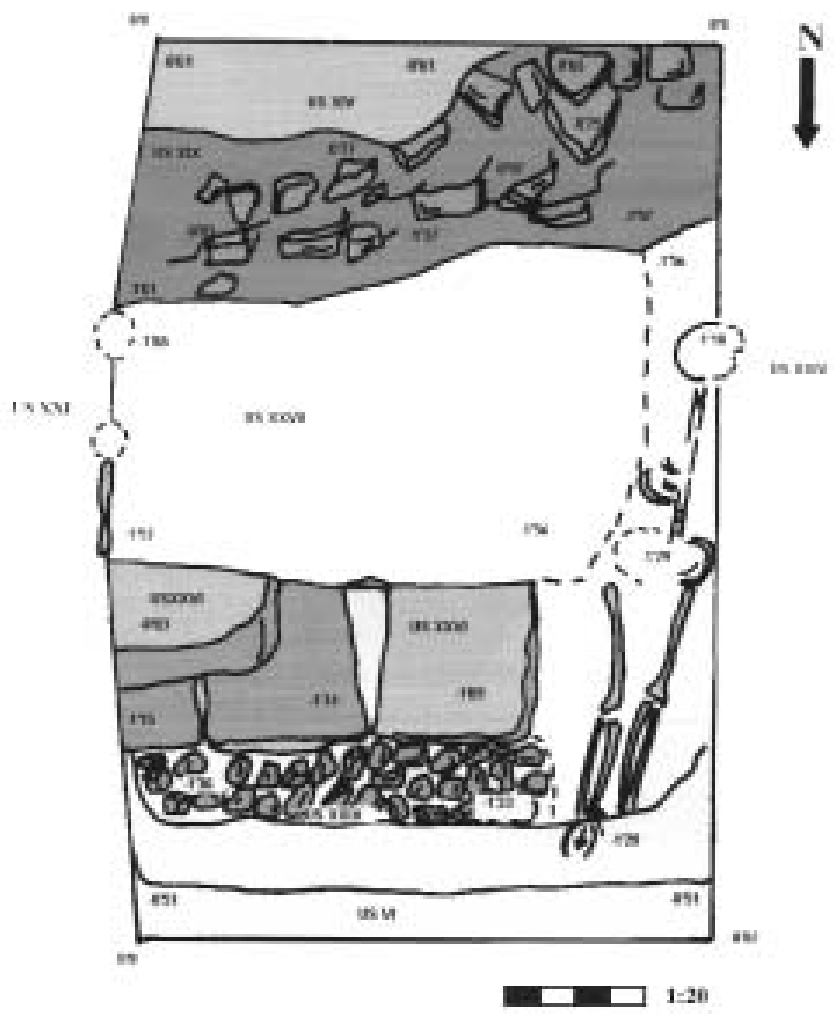

Fig. 4. Planta del corte arqueológico 2
Una tercera fase en la que se detectan tanto restos de muros, que podían corresponder con antiguas habitaciones del Convento de Santa Catalina, como un vaciado de toda la estratigrafía preexistente, hasta los niveles romanos, para su utilización como enterramientos de monjes. Aunque hay varios tipos: algunas en las que se recogen clavos que evidencian la existencia de un ataúd y otros enterrados directamente en el opus caementicium de los niveles romanos y en los que se ha documentado una reutilización de las fosas (con el amontonamiento de los restos óseos a los pies).

\section{HISTORIA}

Este inmueble, levantado, según se documenta en las fuentes, sobre el antiguo emplazamiento de los palacios árabes (MADOZ, 1849) se constituye, pues, como una de las más nobles y antiguas fundaciones jiennenses.

Según el historiador de la Orden Fray Juan López, obispo de Monópolis (en su Historia de la Orden de Santo Domingo, $3 .^{\mathrm{a}}$ parte, libro $2 .^{\mathrm{o}}$, capítulo 85 ), el asentamiento tuvo lugar en los palacios musulmanes, teóricamente localizados cerca de los baños árabes de la placeta de Santa Luisa de Marillac (actualmente conocidos como Baños Árabes del Palacio de Villadompardo): "De este palacio de los reyes moros, que en un principio sería morada del gobernador o wali de la cora de Jaén, nada ha quedado. Cuando fue cedido a los dominicos debió sufrir numerosas obras de adaptación y derribos para construir la primitiva iglesia ojival dedicada a Santa Catalina. No obstante, aún quedaban en el siglo XVI edificaciones árabes. Pero la gran obra renacen- 
tista que se hizo, acabó con todo lo visible. Y si algo quedó, permanece tan disimulado, que, como en el patio de la Iglesia de la Magdalena, sería preciso una investigación para descubrirlo» (ORTEGa SAGRISTA, 1967).

A principios del siglo XI se produce la destrucción violenta de algunos de los edificios excavados en Marroquíes Bajos (zona actual de expansión de la ciudad de Jaén, localizada al norte, y en la que se ha llevado a cabo una gran actividad arqueológica debido a la ocupación constante de ese territorio desde la Edad del Bronce). Al tiempo que desaparece este arrabal, el recinto amurallado crece notablemente, en un proceso general a todo al-Andalus. La profunda inseguridad que se produce tras la caída del califato y los deseos de los nuevos dirigentes de controlar más a la población conduce a su concentración tras las murallas.

En Jaén, además de la ampliación del recinto amurallado, la gran conducción de agua que partía desde la Magdalena (localizada en la parte alta de la ciudad, intramuros) se prolonga considerablemente y se construyen varios ramales menores que llevan el agua a la parte baja de la ciudad. Esta ampliación se justifica por el crecimiento del caserío y por la multiplicación de edificios públicos que necesitan mucha agua y de los que, en esta ciudad, se construyeron varios, como baños, mezquitas, así como el palacio o palacios de los sucesivos gobernadores que controlaron la ciudad.

En la segunda mitad del siglo XII las construcciones de la ciudad alcanzan el extremo sur del recinto amurallado, donde los almohades levantarán una nueva mezquita aljama, que, al menos, triplicó el volumen de la anterior.

Con todo esto, se quiere concluir que consideramos que nos encontramos ante los últimos restos de los «palacios árabes» localizados, según las fuentes y según ciertos indicios de intervenciones anteriores en solares adyacentes, en esta manzana. Igualmente, si atendemos a la técnica utilizada, el tapial, empleando un mortero de gran dureza y bastante cal, que se dispone sobre una base o zócalo de mampostería de diverso tamaño. A este mortero de argamasa se le añaden fragmentos de ladrillo triturado, obteniéndose así una variación del conocido opus caementicium de tradición romana.

Sobre este muro de tapial hormigonado con una base de ladrillos que salva las diferencias de la orografía del terreno, continúa el muro pero con sillares colocados a soga y trabados con mortero, configurando una fábrica de bastante entidad. Consideramos que a ella corresponde la estructura que se levantó cuando el edificio se convirtió en el Convento de Santa Catalina Mártir. La mayor parte de la estructura del edificio se corresponde con este período, manteniéndose aunque perdiendo habitaciones y espacios propios de un convento (cocinas, etc.) y conservando otros (patios, claustro).

Durante el siglo XVI, época de su máximo esplendor, tras su laicización gracias al apoyo económico y moral dado por Juan Cerezo, y, sobre todo, gracias a una bula de Paulo III (1534-1549), se convirtió en Universidad. Sin embargo, Baeza se considera con más derechos a usar el título de Universidad, resolviéndose el pleito a favor de esta última.

Durante la ocupación de Jaén por los franceses a principios del siglo XIX, este edificio fue objeto de una gran destrucción ya que en esta plaza se hicieron fuertes los patriotas. Tras la desamortización, pasó a manos de la Diputación Provincial, que lo convirtió en Hospicio para Hombres, en 1847, realizando profundas reformas, abandonándose en 1970. Tras esta fecha fue objeto de una restauración profunda para convertirlo en sede del Archivo Histórico Provincial.

En este período encuadramos todas las reformas y arreglos que se detectaron en la parte inferior del muro sur. Cronológicamente, se observan distintas etapas de actuación, aunque consideramos que la mayoría de ellas, si no la totalidad, deben responder a intervenciones realizadas entre 1920 y 1980, etapa en la que debido a las necesidades crecientes, se acondicionaría este edificio ya que se mantenía en uso. Nos referimos a infraestructuras como canalizaciones y cableado.

Así, vemos, que gracias a una actuación interdisciplinar, se ha podido documentar de forma científica la lectura histórica de este inmueble y corroborar hipótesis anteriores sobre la evolución urbana de la ciudad de Jaén a través de uno de sus edificios más singulares.

\section{Bibliografía}

Campos López M. a'T, 2000, La Moneda Andalusi en Jaén. Una Introducción, Jaén.

CAmpos López M.a'T, 2001, Estudio murario del muro sur del claustro de Archivo Histórico Provincial de Jaén colindante con la calle Santo Domingo, Informe para la Delegación de Cultura de la Junta de Andalucía en Jaén.

Campos López, M. ${ }^{\mathrm{a} T}$, 2001, Informe sobre el Proyecto de eliminación de humedades del Archivo Histórico Provincial de Jaén, Informe para la Delegación de Cultura de la Junta de Andalucía en Jaén.

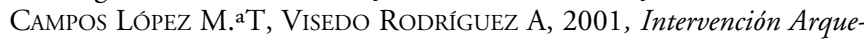
ológica de Urgencia en el Archivo Histórico Provincial de Jaén, Informe para la Delegación de Cultura de la Junta de Andalucía en Jaén.

Castillo Armenteros J.C., Castillo Armenteros J.L., 1992, Nuevos datos sobre el urbanismo del Jaén islámico: las criptas de la Iglesia de San Juan, Miscelánea de Estudios Árabes y Hebraicos, Volumen XL-XLI, pp. 49-65.

Galera Andrew P. 1985, Catálogo Monumental de la Ciudad de Jaén y su Término, Jaén.

Gómez de Toro M.aE., Choclán C., 1989, Informe sobre la actuación de urgencia en la Fuente de la Magdalena (Jaén), Anuario Arqueológico de Andalucía, Tomo III, pp. 310-318. 
JimÉNEZ Y, Chica M.a P, CASTillo J.C., 1991, Excavación arqueológica de urgencia en la calle Baños de la Audiencia, Anuario Arqueológico de Andalucía, Tomo III, pp. 234-242.

LÁZaRo Damas S., 1988, Desarrollo Histórico del Casco Urbano de Jaén Hasta 1600, Jaén.

Madoz P, 1849, Diccionario Geográfico-Estadístico-Histórico de España, Madrid, Vol. Facsímil preparado sobre Jaén. Valladolid, 1988.

OrTega SAgrista R, 1967, La extinguida Universidad de Santa Catalina Mártir de la ciudad de Jaén, B.I.E.G, n. ${ }^{\circ} 54$.

Ruíz Ridríguez A., 1983, Sobre los orígenes de la ciudad de Jaén, Revista de Arqueología n. ${ }^{\circ}$ 27, Año IV.

Salvatierra Cuenca V., 2001, Crisis del emirato omeya en el Alto Guadalquivir. Precisiones sobre la geografia de la rebelión muladí, Jaén.

Salvatierra Cuenca V, Serrano Peña J.L, Pérez Martínez M. ${ }^{a} \mathrm{C}$. 1998, Genèse de la ville islamique en al-Andalus et au Maghreb occidental, Madrid, pp. 185-206.

V.V.A.A., 1995, Informes de la Construcción, Instituto Eduardo Torroja, Vol. 46, n. ${ }^{\circ} 435$, Madrid. 